\title{
THE CULTURES OF THE SOUTH AS COSMOS
}

\section{Nikos Papastergiadis}

\begin{abstract}
As the Global South is increasingly interpenetrated by neo-liberal and authoritarian regimes the idea of the South as a site of emancipatory resistance and exotic cultural difference has ended. This article offers an alternative route into the cultures of the South. It focuses on the shifting forms of the South in contemporary visual art and outlines the possibilities of non-coercive forms of cultural exchange and the cartographies of a cosmopolitanism from below. This perspective on the South is most evident in the stories of embodied solidarity that stand in contrast to top down visions of socio-economic development and cultural homogenization.
\end{abstract}

\section{KEYWORDS}

South, Culture, Cosmopolitanism, Antipodes, Documenta, Contemporary art

What is the nexus between the territory of the South and the world in the cultures of the South? Let us consider this question through the complex constellation of chromogenic photography and acrylic painting by Ian North: Seasons, Australia, Kongouro (1987). The image is in four parts, or it could be read as four images arranged as a cross window, or as four panels on a flag. Inside each frame is a second image with a giant kangaroo perched on a rock. Its neck is in full rotation, surveying the tough landscape behind - this rotation of the neck is something that a dingo can also do but no other dog can. The odd spelling of the talismanic animal in the title Kongouro mimics the pronunciation of many post war migrants in Australia. Seasons: all four of them, captures the mysterious fluctuations of light, which with its unique hemispheric hues baffled the early European Painters. It took almost a century for painters in Australia to learn how to unsee the landscape through the European filter. Since the 1970 s, in the work by painters like Fred Williams and the legendary indigenous art movement that began in 
Papunya Tula, we have witnessed a flurry of experiments in form and perspective. In North's image there is also the subtle contrast between the ridge of mountains, whose peaks appear to be sanded down to a bumpy contour, and a snake-bend road. The road is a scar, but it seems temporary rather than as definitive conquest over the land. Finally, there is the question: From where does the viewer gain a vantage point? High up on another mountain - this would be in keeping with the picturesque European panoramic optic, but then this God's eye viewpoint is disrupted with the multiplication of inlaid panels. There are as many focal points as there are panels, and despite this interplay the horizon recurs as a continuous line.

These four themes in North's image: Kangaroo - the hybrid creature, mouse mixed up with foxes; light - a mysterious force that stuns the eyes; geography/ontology - a land without frontiers; and optics - the problem of perspective, these are also the major themes that run through the idea of the cultures of the South. Thus going south is not a geographic destination, but in the course of this essay will be another heading that leads to the mercurial conjunction of art-worlding. This approach is all the more necessary given that the cultural and political visions of the South have come to a crossroad. In this article I will argue that the idea of the Global South was linked to an emancipatory ideology that was deeply entrenched in both Western Enlightenment values and non-Western indigenous knowledge systems. Both traditions have been eviscerated by the triumph of neo-liberalism. The political landscapes of the Global South and the North have been hollowed out. They are increasingly in a ruin state that only serves primordial neo-nationalism and rampant individualism. As a creative counter force, or even as a distinctive entity in a relational field, the idea of the Global South is now over. A deep interpenetration of the spheres has dislodged the link between socio-political agenda of the Global South and the cultures of the South. However, as a cultural concept the South is heading in new directions. This article offers a brief outline of some of the founding theoretical conceptions of the South as a creative counterpoint and critical partner to the North, and then sets out to explore the recent cultural manifestations of the South in the context of contemporary art. It is from the ruins of the older emancipatory discourse and the emergent pluriversal cultural images of the South that a new perspective on cross-cultural dialogue and transnational solidarity is emerging. From this vantage point I will also speculate on the viability of the South as heading for rethinking cosmopolitanism from below. 


\section{WHERE IS THE SOUTH?}

The location of the South as a cultural heading does not neatly correspond to a fixed geographic region. It is dispersed in a non-contiguous manner across both sides of the equatorial divide and its formation is derived more through the oscillating pathways of connections, than as an aggregation of representatives from distinct territorial blocks. Speaking of the cultures from the South is not the same as speaking of culture in the territorial zone of the South.

The signification of South's cultural context is also loosely structured by a postcolonial agenda that includes a common awareness of residual colonial legacies, the ambivalence of settler domination over indigenous societies, and the subsequent invention of new hybrid forms of self-affirmation and cultural identity. However, the status of culture and logic of cultural transformation in the South does not neatly correspond to the bi-polar perspective of the uneven development thesis that is dominant in socio-economic and geo-political understandings. A different dynamic is at play in the cultures of the South. The conventional path-lines towards progress and measures of value are disrupted by accounts of cultural production in which leaps and surpluses are discovered without the presumably necessary infrastructural underpinnings, or access to discursive networks. Gerardo Mosquera has gone so far as to claim that the trajectories and bursts of cultural production from the South have the power to disrupt the binaries that dominate the paradigms for representing the locus of innovation and influence in contemporary art. ${ }^{1}$ However, by highlighting these mobile and ambivalent processes, it also presents new challenges in identifying and mapping the culture of the South.

From these ideas on the dispersed location of the South, and the South as a platform for challenging the hegemonic cultural views, there was also a demand for a new understanding on the relationship between culture and society. The cultures of the South tended to be defined from a relational perspective on cross-cultural interaction and through a bi-focal perspective towards cultural consciousness. These approaches necessitated the adoption of modes and models of evaluation that were a departure from those utilized to define the geo-political context and measure socioeconomic transformations. Therefore the culture of the South was not confined to being either a representation of the political infrastructure or a response to the economic conditions of the South. The culture of the South had the capacity to generate alternate and wider visions of social relations and systems of exchange. In the past decade the politics of the South have gained a renewed 
emphasis in the field of culture. Questions that have come to the fore include: Can the culture of the South produce new understandings of equality in the context of cross-cultural dialogue? Is the space of the South more conducive to non-coercive form of exchange? In short, can the South provide an autonomous platform that breaks from the hierarchies and oppressive polarities in the North? Or does the inter-penetration of the North and the South mean that the oppositional identity has ended?

These are vast and radical questions. They carry much of the open-ended hope that was evident in critical moments of decolonization such as the Bandung conference, but they also point to the limits of the ideological formations that shaped the early periods of the South as an emancipatory idea. Hence, rather than celebrating the production of new critical visions, it is also vital that we clarify the body of thought from which they arose and also speak to conditions of contemporary cultural production. To grasp the distinctive vision of the cultures of the South requires a paradigm shift. Culture is not a bi-product of economic development and an outcome of the infrastructure imposed by political elites. The cultures of the South are more complex than such deterministic and paternalistic models would anticipate. The cultures of the South emerge from both the depth of everyday practices of survival and the breadth of interaction with far-flung forces. It will be necessary to both zoom in on the grounded context of production and zoom out to appreciate the widest possible spheres of connection. This dual approach produces a tension in the categories of evaluation. At both ends a cosmopolitan agenda is evoked. In both the intimate conditions of production and the immense expressions of connection there is an invitation to others and an openness to ideas that is non-exclusive. Despite this promise of solidarity and the desire for equality there is a problem that arises from the place and perspective from which the other and difference is beckoned. Is a grounded form of cosmopolitanism or even what is referred to as the cosmopolitanism from below a contradiction in terms? Is a cultural view that starts from the South and then moves both inwards and outwardly a restricted, or at best, a strategic adoption of cosmopolitanism? These questions unsettle many of the more open-ended claims about the cosmopolitanism that arises from below and the significance of specifying an originating locus point for a transversal form of cosmopolitanism.

In broad terms I want to examine the way the concept of the South has been stretched across a number of contradictory fronts. It has been mobilized to sustain an emancipatory rhetoric through 
the adoption of an anti-colonial normative conduct, an aesthetic sensorium that is delinked from the Western tastes and sensibilities, and co-opted to justify a new geo-political order that is lead by the BRICS. The liberalization of markets and dismantling of colonial regimes have radically opened up the processes of economic and political participation. However, there is often a profound rift between the conceptual claims about the South and social transformations in the South. The new global order has neither supported the process of democratization in the South, nor stimulated new transnational modes of solidarity between the South. To find signs of South-South networks that are more open to the ideals of equality and emancipation, we will need to look closer at the cultural experiments in representation and social interaction. As the focus moves towards the cultural and aesthetic articulations of the South I will be noting the formation of a new kind of cartography or cosmos of the South. These new mappings no longer refer exclusively to territorial units of belonging or move through abstracted claims of solidarity. Rather, they point to the possibility of affinities from a more nuanced process of recognition and sense of co-existence amidst the fractured expressions of cultural attachments and finally they point to the widest possible spheres of civilizational interconnectedness that combines both embodied and celestial perspectives.

\section{WHAT IS THE SOCIO-ECONOMIC AND}

\section{GEO-POLITICAL STATUS OF THE SOUTH?}

First let us step backwards and examine how the concept of the South was adopted as a metaphor for uneven socio-economic development. The foundational reference point is the ironically incomplete essay "Some Aspects of the Southern Question." 2 The Italian communist Antonio Gramsci was working on this essay just prior to his arrest by the fascists in 1924. In this essay - which juxtaposed a series of detailed observations on the concentration of the Italian bourgeoisie in the industrial North, with an acerbic critique of the relegation of the peasant based society of the South as an internal colony - Gramsci outlined both his sensitivities to regional consciousness and a revolutionary strategy. Born in Sardinia, Gramsci was profoundly aware of the centrality of regional attachments and cultural cleavages that both over-rode and cut across class differences. Hence, he argued that the emancipation of the South is not engineered through the singular leadership of the proletariat, but through a hegemonic consensus with the peasantry. 
This dual perspective on the specificity of regional consciousness and the political value of consensus has been a philosophical cornerstone of development studies. Aspects of Gramsci's approach have also been influential in the policy work of NGOs and projects by transnational agencies such as the UN. Despite the regular summits on collaboration and fostering of trade networks the levels of inequality in the South did not decline. On the contrary, by the 1990s the "developmental gap" - that was imposed by the colonial regimes and accentuated by the industrial models - widened in the era of global markets. There was a growing recognition that the South was once again being relegated to a source of raw material and cheap labor, while the North was the place of high service skills and refined modes of production. As global networks intensified there was growing evidence that the socio-economic conditions of the South were being devalued and increasingly bypassed. Hence, new social movements have emerged that opposed the growth of corporatist power and called for new terms for fair trade and global justice. ${ }^{3}$

In geo-political terms the South also registered as the excluded part of the North: an aggregation of North America, Western Europe and East Asia. The South now encompasses much, but not all, of what was previously captured by the terms Second and Third world. As a geo-political category it also tends to operate within the bi-polar hierarchies of lack and surplus and the "developmental" dynamic of central accumulation and peripheral deprivation. However, the rapid rise of the BRIC economies has produced a new cleavage in the outlook of the South. This has encouraged some commentators to present the optimistic view that the emergence of South-South networks will both dislodge the monopoly of the North as it extends the networks of power and hegemony. Whereas the more sceptical view has stressed that the geo-political balance will not shift if there is just the relocation without the disaggregation of global power. ${ }^{4}$ In contrast to Gramsci's revolutionary model of coalition and consensus the function of the South that has dominated in the discourse of globalization has been premised on increased opportunities for competition. The consequences in the South have been of increased inequality and the perpetuation of oppression.

\section{THE CULTURAL THEORIES OF THE SOUTH}

In the same year that Gramsci was composing his revolutionary notes on the "Southern Question," the Uruguayan painter and writer Pedro Figari published his influential essay "Autonomia 
Regional.”5 Figari had recently returned from Paris where he had been exposed to Post-Impressionism. However, rather than coming back to the "provinces" with the aim of passing on a superior style and optic he concluded that South American artists must wrestle with European influences in order to develop their own vision. He moved to Buenos Aires, mingled with Luis Jorge Borges, and celebrated the gaucho landscape in lyric forms. Within a few years, the literary magazine Sur was published in Buenos Aires. Victoria Ocampo funded this magazine and a number of residencies for prominent artists and writers in order to deepen the exchange of ideas between the North and South. ${ }^{6}$ This combination of nativist and dialogical perspective has remained a powerful force in the institutional development of Latin American art. For instance, at one end of the spectrum there was the powerful curator and critic Jorge Glusberg who promoted the "autonomy" and "transformative approach” of Latin American art. ${ }^{7}$ However, such a utopian view was disputed by critics such as Juan Acha who persuasively argued that Figari's vision of a unique regionalism was expressive of a desired ideal, rather than reflecting the actual reality of Latin American culture. ${ }^{8}$

The tension between cultural specificity and relative autonomy within regional identity is not confined to the debates in Latin America. It recurs in almost all the debates on the cultures of the South. The pioneering work by Bernard Smith on the distinctiveness of Australian art practice spanned the period between 1945$1960 .{ }^{9}$ It was in this critical phase that Smith proposed the concept of the Antipodes, not as a negative polarity, but as a relational mode for thinking to the other. For Smith, Europe was Australia's antipodes. He had the perspicacity to identify the conceptual distortions and empirical deficiencies that resulted from simply adopting and extending Eurocentric frameworks and approaches in the context of the cultures of the South. He also noted that artists in Australia responded to their specific cultural predicament and environmental forces in a distinctive manner. Like many scholars of his generation, Smith was also painfully aware of being trapped in the polemics that swung between the cultural cringe and defensive insularity. ${ }^{10}$ This was a re-run of the assimilationist versus the creative synthesis models of cross-cultural exchange. Both positions risked becoming entangled in a self-defeating reaction. However, the way out of this impasse was not self-evident. Or put another way, the first generation of cultural critics from the South may have been astute in identifying the substantive differences in the cultural formations of their place, but they also tried too 
hard to report back on these observations and give form to their insights within the conceptual frameworks and hierarchical value systems of the North. In short, their method of representation was not as hybrid as the hybridity they observed in their subject and this problem has continued in recent art criticism. ${ }^{11}$

Writing a generation later than Bernard Smith, and from the vantage point of New Zealand, the poet and curator Ian Wedde made a further step in articulating the complex entanglements of cultures in the colonial contexts. ${ }^{12} \mathrm{He}$ observed that through the "ironic appropriation" of colonial symbols and the awareness that oral indigenous knowledge systems are not commensurate with document based archival histories, there is a production of an "ambiguous space" - one that exists "between research and history, between recovery and tradition.” Wedde shifted the focus from a mere lament for the absent authentic indigenous cultural records to an exploration of the mediated claims of the past. Such mediated claims are embedded in the colonial project. Hence, Wedde noted that indigenous artists in the South Pacific developed an ambivalent fascination with the colonial archives of their own past. These "modern" records of the colonial contact zones provided a haunted starting point for visual detournement. It inspired artists to not only confront the gaps and distortions in their own historical legacies, but also re-route many of the colonial symbols and fantasies. For instance, the European fantasy of arcadia onto the South was turned by the colonized into a stimulus for double consciousness of an impossible but desired utopia: "to believe again in what it knows does not exist”. ${ }^{13}$

In the founding texts on the culture of the South we witness ambitious voices that seek at first to clear the ground of the colonial misconceptions, to destigmatize the status of local culture, to demand an open and equal basis for cultural dialogue, but we also witness a recognition of the inevitably uneven terrain upon which this exchange occurs. Given the violence of the colonial encounters and the disruptions of indigenous knowledge systems irretrievable gaps and incommensurable differences are part of the conditions in which contemporary culture is produced. And it is on the basis of the perpetuation of these tensions that we can sum up the key themes of this period under two theses:

\section{Thesis 1}

Distance and dislocation from the metropolis as an affordance for the semi-autonomous development and experimentation in alternative forms. 
Thesis 2

Incommensurability as a spark of innovation: the old world's methods do not apply and the promises of the new world do not fit. The tension between naming and experience is a spur for conceptual break. The affirmation of new subjectivities thus rests not only on inverting stereotypes, but also a revaluation of the intimate formations that arise from the conjunction of naming and producing an emergent hybrid subjectivity.

\section{SOUTH AS A FRAME FOR}

\section{REPRESENTING THE OTHER}

The context of contemporary art has been one of the most prominent sites for the articulation of the idea of the South. At first it was presented as a general category to capture the non-Western Other. As artists, curators, and writers in the South gained greater visibility in the North the idea of the South gained traction as an oppositional and critical counter-point to the Eurocentric visions of modernism. These figures were quick to point out both the innovations that occurred in the South and the conceptual flaws in the Western discourses. The institutions of the West were vulnerable to the critique that there were fundamental biases and gaps in their claim to being a universal holder of cultural knowledge. Museums and biennales started to respond by developing themed exhibitions that aimed to expand the frame of contemporary art and deprovincialize the imagination.

In a series of exhibitions that include "Primitivism" in the Twentieth Century, MoMA, New York 1984, Magiciens de la terre, Paris 1989, and Il Sud del Mondo, Marsala 1991, there was a concerted effort to "introduce" the artists from the South into the North. However, the category of South was ambiguous, in geographic terms it tended to refer to anything outside of Europe and North America, and as an aesthetic category it was primarily designed to capture indigenous artistic practices as a form of exotica that would complement rather than contribute to Western traditions. However, in the South and in exhibitions curated by leading figures from the South a different perspective had already emerged.14 For instance, the Sydney Biennale opened in 1973 and by the late 1970s the curator Nick Waterlow had pioneered a series of critical dialogues between indigenous and Western artists. In 1989, the artist Rasheed Araeen curated the seminal exhibition The Other Story at Hayward Gallery, London, and Gerardo Mosquera curated the third Havana Biennale that had the explicit aim of building a South-South platform for a critical regionalism that affirmed the 
cultural survival in the peripheries. These path-breaking exhibitions set up a template in curatorial focus that challenged the Euro-American hegemony over cultural innovation, identified new sites for the dissemination of contemporary art, proposed alternative narratives of cultural exchange and outlined a new history of artistic globality. From this point on, the idea of the South as an aesthetic and cultural category was no longer confined to a closed tradition in the remote corners of the world, but became a metaphor for the critical dialogues and hybrid cultural practices that arose from the complex entanglements of colonial and settler cultures.

A measure of the move from the destigmatization of the South as a geographic destination for cultural backwardness to a murky metaphor for a relational cultural modality can be found in the reworking of the artistic representation of the southern hemisphere. Joaquin Torres Garcia's America Invertida, 1943, literally flipped the image of the world on its equatorial axes. The South is up and the North is down. With this simple inversion there is also a reversal of order and direction. This aesthetic mapping of the top and bottom of the world recurred in Heri Dono's Untitled, 2012. Dono is an artist based in Indonesia which like the continent of South America straddles both sides of the equator. Dono adopted Garcia's geographic template, however, he also overlayed it by sketching in a hybrid figure, part/man-part/serpent. This mythical figure is depicted dreaming of birds in flight that both head towards and form the pattern of the celestial Southern-Cross.

At around the same time that artists from the South were inventing new frames for representation there was also a shift in the theoretical discourse on the South. The London based journal Third Text was launched by Rasheed Araeen in 1987 and in 1990 Nelly Richard founded Revista de Crítica Cultural in Santiago, Chile. These scholarly journals provided new reference points for examining the redemptive approaches towards the South and challenging the expansionist strategies in Western art institutions, while also initiating investigations into the creative potential that arises from the clash between Western and non-Western cultures and a wider understanding of the multiple modernities that were formed throughout the world. In the 2001 conference held in Sydney, Globalization + Art + Cultural Difference - On the Edge of Change, keynote speakers such as Gerardo Mosquera and Carlos Capelan proposed that the emergent South-South circuits had the potential to pluralize the possibilities of being global. ${ }^{15}$ This led to a new initiative: The South Project. Running for almost a decade, this project explored the horizontal cultural perspective that looped 
from South (Oceania) - South (America) - South (Africa) and materialized this Southern vision through a series of artist exchanges and collaborations between these continents and across this hemisphere. ${ }^{16}$

Throughout these diverse theoretical explorations and artistic experiments there was an unequivocal expansion in the field of contemporaneity and a concerted effort to deprovincialize the imagination. In 2010, curator and theorist Cuauhtemoc Medina hosted a conference in Mexico City and announced that the reference points of the South in a quadruple format: Sud-Sud-Sud-Sud. His invocation came with the challenge to assess the extent to which the South had acquired a "new critical and productive importance in the fabric of global imagination.”17 By 2012 the spirit of cultural inversions and postcolonial trickster resurfaced in the Athens based journal South where stereotypes were mocked and geographic boundaries eschewed to the extent that the subtitle declared itself to be no less than "a state of mind." After its fifth issue the journal was rebranded as temporary "host" to the publication wing of documenta XIV. On the other side of the world an emerging collective of scholars launched a journal with the curious title Southeast of Now: Directions in Contemporary and Modern Art. Following from the example of Third Text, this journal gave itself the task of challenging the still prevailing dichotomy of center and periphery and shifting the points of focus away from the North and West. The reversal of the conventional order from modern to contemporary also signaled a historical perspective that acknowledged the complex temporalities and lineages within the region.

It is too early to determine the impact of these recent efforts to use the South as a Global frame for contemporary art. However, it is important to stress that biennales and documentas have been major crucibles in the formation of this new frame. Their function began with a cartographic intent - the global survey of contemporary art - and in the past two decades this has been complimented with a discursive mission: to be platforms for the articulation of the new. The admission of a discursive dimension in the arena of contemporary art provided an opportunity to reflect on the limitations of the dominant paradigms and create a wider conceptual framework. As documenta XI was a watershed moment in terms of both engaging with the culture of the South and expanding the theoretical worldview of contemporary art I will now dedicate a special focus on this exhibition. 


\section{DOCUMENTA XI}

Okwui Enwezor declared that the curatorial vision for documenta XI was driven from the "sheer side of extraterritoriality." 18 Under this heading Enwezor brought together the links between slavery in the South and industrialization in the North and threaded them into the uneven history of the decolonization movement, displacement of refugees and migrants, the instability of borders, the emergence of hybrid cultural identities. Enwezor's distinctive intervention arose from his injection of "extraterritoriality" into the three trajectories that defined the structure of the exhibition as a project. First the framing of the exhibition of documenta XI was decentered by initiating an extensive program of events in locations outside of the historical center of Kassel. Prior to the staging of the 100-day event in Kassel (June 8 - September 15, 2002), Enwezor had already developed the "project" by and through four continental platforms for addressing the key issues of creolization, justice and reconciliation in Europe: Vienna, Berlin; Americas: St. Lucia; Africa: Lagos; and Asia: New Delhi. In each of these platforms ideas were contested, explored and expressed in a variety of voices and gestures.

Second, there was a cross-hatched mapping of the cultural consequences of decolonization in the South and de-industrialization in the North. This culture of the South was manifest in the complex topologies and hybrid symbolic repertoire produced by artists such as Yinka Shonibare, Chris Ofili, Steve McQueen and Stan Douglas. In more modest tones it was also evident in Chohrey Feyzdjou's obsessive cataloguing of burnt materials in the eponymously named trunks and containers, Sanja Ivekovic's ongoing documentation of the process of soliciting and reconstructing her mother's official records and Destiny Deacon's journey to her mother-land in order to construct imaginary scenes of an absent postcard communication. Alongside and cutting into this trajectory was a survey of both the artistic expression of the utopian promises of modernism and the artistic responses to the dystopian ruins of post-industrial spaces. This contrast between the optimistic belief that modernity, and the power of industrial innovation, as expressed in the images, models and maps that Constant, the Dutch visionary, produced for his imaginary city "New Babylon," could not be registered more starkly when they were juxtaposed with Pavel Braila's ghostly video of the changing of railway gauges at the rusting and jutting junctures within the former Eastern bloc railway networks, and Allan Sekula's photo-narrative Fish Story which chronicled the struggle amidst the demise of the seafaring and dockland communities. In this 
survey, there was not just a depiction of the tarnished post-industrial world, but also an argument about the task of the artist. According to artists like Bargmann and Levy who described their practice in the form of a "clean-up" operation, it shifted from dreaming the utopian modernism to dealing with the dystopia that surrounded urban life. Yona Friedman also stressed that the task of the artist shifted from invention to re-cycling, from expressing a new vision for the future to developing new ethical collaborations to deal with the legacies of the machine age.

The third trajectory in which "extraterritoriality" featured in Documenta XI was the reconfiguration of the gallery space as a discursive platform and the incorporation of expanded models of disciplinary practice. The introduction of a cultural perspective that combined post-colonialism in the South with post-industrialism in the North, interdisciplinary practice that drew from recent innovations within and between the borders of literary theory, political philosophy and anthropology, the engagement with wider social and theoretical debates on cultural identity, could be seen in the work of collaborative artists like Thomas Hirschhorn and collectives like Multiplicity (Milan), Raqs Media Collective (New Delhi), Le Groupe Amos (Dakar) and Huit Facettes (Kinshasa). ${ }^{19}$ These collectives' work define the practice from beyond and within the institutions of art, they draw on technical experts in order to create connections with social groups, and develop new political strategies of expressive resistance. Their engagement with everyday life, especially the codes and symbols of popular media culture, is not confined to invigorating the discourses of art, but an admission that art belongs in the same time / space continuum of popular culture. Thus, they claim that the place of art is no longer aiming to be an elevated or a belated response to everyday events, but rather as Charles Esche argued, it is now "positioned in the territory between active political engagement and autonomous experimentation." 20

The aesthetic appeal of ruins and the parafunctional uses of abandoned materials, the conjunction of a discursive turn with interdisciplinary collaborative practices and the construction of counter-memories and hybrid subjectivities from the colonial encounters provide the three extraterritorial trajectories of documenta XI. Enwezor's project provided both a much needed stimulus to curatorial projects that an emergent generation of curators described as both making a more "direct cartography" of the North-South border zones, ${ }^{21}$ and expanding the form of art historical thinking that takes "critical transregionality" as an "armature of place across our planet.” 22 The heading of extraterritoriality 
served a vital role. It exposed gaps and opened up new directions. Enwezor had argued that it was not enough to integrate the artistic movements from the South into the canon of the North. ${ }^{23}$ The arrival of the South required a transformation in the framing of culture. Hence, the concept of extraterritoriality sought to dislodge the Eurocentric categories that subordinated and marginalized the culture of the South. However, it also encountered the fate of conceptual co-option within the hegemonic discourses in contemporary art, as well as being overtaken by the shifting role of culture in the neo-liberal regimes. The oppositional and even relational status of the broader concept of the Global South and the specific heading of extraterritoriality were increasingly absorbed in the globalizing trajectories of contemporary art. The critique that documenta initially presented in relation to the discursive frameworks of contemporary art - the admission of new regions into the debate of world art, the exposure of the structural limits and biases in conceptual hierarchies within art history and the introduction of key terms from postcolonial cultural theory into critical reception of contemporary art - was soon to be overtaken by new levels of cross-cultural interaction and deepening forms of geo-political interpenetrations. To witness the challenge that now appears amidst the global cultural landscape it is worth mapping the changing conceptions of the South in the recent theoretical reflections and curatorial interventions.

\section{SOUTHERN THEORY}

The first shift in the concept of the South is its elevation as an explicit category for understanding global culture. In the wake of the prominent role played by postcolonial theory and history both within the academy and the artworld, there was in the 1990s an emergence of what the sociologist Raewyn Connell called "Southern Theory." 24 The production of this theoretical discourse has emerged against the grain. For as the Singaporean based critic and curator Weng Lee Choy observed even in this region, which has invested heavily in arts infrastructure in the past decade, it still lacks a "discursive density." ${ }^{25}$ In nearby Australia, the sociologist Peter Beilharz noted that: while the $20^{\text {th }}$ century reforms to welfarist agenda, innovations to legal institutions and experiments in cultural identity where of such a scale that he could proudly speak of an Antipodean Civilization, the more recent advances of neo-liberal ideologies have amounted to a radical retreat from the earlier gains to regional autonomy and socio-economic equity across the South. ${ }^{26}$ If the discursive formations are lacking and 
the ideological conditions are in retreat, then how does a southern theory stand a chance in shaping the cultural imaginary in the era of neo-liberal cultural commodification? Does this predicament return us to the center/periphery dynamics of the colonial era, whereby the South, while lacking access to metropolitan discourses and infrastructure, was able to preserve a relative surplus of authentic cultural value, and due to the "tyranny of distance" from the metropolis it miraculously spawned aesthetic innovation? Or can Southern theory draw on the scholarship produced in post-colonial and diasporic studies to generate a robust critique of the new world order?

These challenging questions provide the starting point of the Decolonial AestheSis manifesto produced by a collective of artists, curators and writers. ${ }^{27}$ In this ambitious text they acknowledge that the neo-liberal logic of cultural commodification has transformed the cultural landscape of the South, and they also propose that the definition of the South must go beyond the inverse or excluded part of the North. Hence, they begin by declaring the need to "delink" their manifesto from the troika of Eurocentric philosophical models, nationalist agendas and globalizing discourses. This manifesto advances through a double move: it involves both unveiling and reconfiguring the hegemonic nexus between modernity and rationality - through which the West constructed its distinctive framework for concepts such as identity and belonging; progress and innovation. To produce this "radical uncoupling" they propose two conceptual headings that redefine the perspective on subjectivity.

First, they assert the idea of "transnational identities-in-politics" which is an affirmation of identity in its multiple formations that has resisted the homogenizing forces of globalization. These identities are not just fragmented by the disruptive force of globalization, but also formed through the embodiment of a pluriversalist worldview. Identity is formed through the interplay forces that are of a given place and from elsewhere. This perspective does not assume a universalizing standpoint, but rather is formed through a transversal process of connection. And yet, within this relational modality, which is similar to Smith's claim about Antipodean relationality, there is also a strategic execution of universalism: one that is always undertaken from a distinctive landscape: location and history, and this point of departure will "possibly" produce a unique trajectory and a difference in perspective - a hybrid viewpoint.

Second, the Decolonial AestheSis collective also claim that decolonial aesthetics is a liberation of sensing and sensibilities from 
the territorial and instrumental paradigms of coloniality. It will encourage a ground-up perspective on intercultural exchange and lead to the "re-inscribing, embodying and dignifying [of] those ways of living, thinking and sensing that were violently devalued and demonized by colonial, imperial and interventionist agendas as well as by postmodern and altermodern internal critiques.” As Walter Mignolo, one of the authors in the Decolonial AestheSis collective, had argued elsewhere, the cultural logic of transformation is not confined to gaining admission into the existing frameworks of power, but more explicitly linked to the jagged process of inventing a language that affirms the occluded sensorium and cosmologies. ${ }^{28}$ Hence, he concluded that a more radical act of "epistemic disobedience" is necessary: one that will ultimately overtake the term Global South, as it focuses on the productive force of being at the interstices of the global order, and being formed not just in acts of resistance, but also through the experience of the as yet not fully recognized responses to hegemonic globality. ${ }^{29}$

The invocation to "epistemic disobedience" slips us back into the residual complicities with Northern authority and also risks reinscribing a homogenized view of the North. ${ }^{30}$ To be summoned to disobey reminds us that the condition of subordination is not over. While the manifesto strikes a suitably defiant tone and synthesizes complex arguments on the transversal formations of politics and subjectivity, it says little about the need for democratization and calls for further attention to the narratives that can make sense of the complex lifeworlds from the South. Such invocations are salutary markers of the scale of the problems. The forces of globalization that have succeeded in flattening surfaces and removing barriers for commerce, but as Isabell Stengers has argued, this integrative economic agenda has its limits and paradoxes. There is a desperate need for a cosmopolitics that equally extends rights to all humanity, and paradoxically, in the cultural sphere: A globe that is rendered culturally homogenous is a place without a world. ${ }^{31}$ The resistance to the instrumentalization of culture and the global spread of American culture has been at the forefront of the 2005 UNESCO Convention on the Protection and Promotion of the Diversity of Cultural Expressions. Such conventions are valuable policy initiatives in so far as they are an index of the existing threats to local culture and platforms for shared principles, but they have little power to intervene and resolve disputes. ${ }^{32}$ At the micro-level of cultural transformation new tensions are emerging at the interface of local, regional and global forces. The mapping of the mobility amongst artists and curators across the South East 
Asian region by David Tey33 and the controversy over the stunted adoption of International Art English in non-metropolitan art institutions are further indicators of both the heightened diversity and striated means of communication that are now shaping the art worlds. This network of flows and expanded field of cultural production has led one of the luminary figures in art history to conclude that there are now so many worlds in the art of the artworld that it is now impossible as a curator to be a global surveyor. ${ }^{34}$ No frame is big enough and no system has the capacity to coherently accommodate this super-diversity.

Zooming back to the cultural predicament of the South we are still left with the gaping question of how to make sense of these turbulent lifeworlds. According to Natasha Ginwala the cultural representations forged across the South are presenting a new horizontal perspective on belonging. Lifeworlds are no longer predominantly told by unpacking a linear journey to a singular destination accompanied by a resounding account of development and redemption. On the contrary, the "cosmos" of the South unfolds as a diasporic network that is forged in the narratives of mingling with different people and mixing together of traditions from different places. These stories do not offer any unified vision of globality but rather produce a world wide web of knotted fragments. ${ }^{35}$ In these stories a new kind of "cartography" is woven into existence: one that is constituted through the choreographic manoeuvres that interweave motion and mooring. Ginwala informs us that the narrative form tilts from a vertical excavation of personal interiors to horizontal axis that traverses across multiple temporalities and a sense of place that is not defined through a pre-existing location that marks the center of world. This web of fractured stories and accounts of oscillating patterns of movement is both a practical linking together and the order making activity of the diasporic world. It does not fit into the homogeneous, flat world discourses, or the binary algorithms of market hungry globality. However, beyond demonstrating that these diasporic narratives are not commensurate with the globalization discourse, Ginwala is also proposing a distinctive optic and frame for thinking through the cultural expressions from the South. Ginwala adopts terms like "cosmos" and "cartography" to frame the contemporary cultural texts. The South is conceived as a composite locality formed by a "cosmogenic agency," the "contingencies of circulatory flows of thought models" and the "materialities of liberation." This widens the scope and alters the perspective that was previously associated with hybrid formations. The hybrid is not just an eccentric 
expression of subjectivity and the diasporic is no longer confined to a form of cultural production that arises from the contingencies of displacement. These categories are now defined as part of a cosmos: a civilizational modality for seeing the whole.

\section{ALL THE WORLD'S FUTURES:}

\section{THE INTERPENETRATION OF THE SOUTH AND NORTH}

A cosmos is usually understood as a synonym for the universe. In Ancient Greece it had a more layered range of meanings. It referred to an intermediate zone between the earth and the unbounded universe; it was a circumambient sphere that was also the source of the divine and creativity. However, cosmos was also a term used to denote the whole of humanity, and perhaps, most relevant for our purpose it also articulates the activity of organizing time and space so that it is both attractive to the other, and meaningful for the self. Cosmos is thus both the widest ethical concept for belonging and an aesthetic category for the activity for making order out of chaos. The art of cosmos is not just cosmetic in the modern sense of decoration, but a mode of placing one's body in the world so that it is attuned to the harmonic motion of all time and space. Hence, we can claim, that the features of the cosmos are primarily registered through the interplay of ethical and the aesthetic. Cosmos thus comes to absorb the experience of hybridity and the condition of the diaspora: both are incorporated into a wider process of becoming. The definition of the cosmos is no less found in physics than it is produced in the encounters with others. It exists in the journey and all the relations that are formed through motion. The matrix of these relations creates a cluster of inhabitation. Cosmos is the community that forms through motion and communication, the co-existence with others and the effort to create an order that can hold you together. Cosmos is an ordering of place from the chaos of motion, so that world is attractive and meaningful enough to sustain relations with others. By defining cosmos from this dual perspective, Jean-Luc Nancy's statement on art as a world making activity also comes closer into focus:

All art is cosmological, since the productive technique of spacing always produces the world, an ordering of the world, the world in part or as a whole, but always and each time the whole in each part. The world is only ever the infinite reference of each one of these points to all others, and what we call a work of art is, each time, a singular, monadic, and nomadic correction of the cosmos. ${ }^{36}$ 
It is from this perspective that I now reflect on the kind of world that is manifest in Okwui Enwezor's most recent project: "All the World's Futures," Venice Biennale 2015. Of course, we could zoom into Emily Kame Kngwarreye's cosmic painting Earth's Creation, $1994^{37}$ which occupies a central position in the Italian pavilion. Instead I wish to highlight both the interpenetration and critical resistance in the cultures of the South. I will do this by zooming out and think of the cosmos that is formed by the exhibition as a whole, and in particular, I will examine how a powerful conjunction of aesthetic and normative claims was articulated within the architecture of display. In particular, I wish to stress that the formal innovations proposed by Enwezor are in themselves a response to shifting relationship between culture and politics in neo-liberal contexts. The disjunctive format in the curatorial design is connected to the discursive frameworks and substantive issues of engagement. These complex relationships suggest that the cultures of the South can no longer proceed under a single heading. Not even the earlier heading of extraterritoriality is robust enough to integrate the logic of cultural production. What transpires from Enwezor's curatorial and theoretical intervention in the 2015 Venice Biennale is not another critical supplement to world art, but a staging of the very polarities and tensions of the global predicament. The cultures of the South thus surface not just as a source of destigmatized entrants in a competitive arena, ${ }^{38}$ or as carriers of alternative modernities that can widen the global cultural archives, but as a cosmos that can revive the sense of difference in the world.

In the heart of the Venice Biennale is the Italian pavilion. In the middle of this pavilion Enwezor installed an "Arena" that was dedicated to talks, performances and lectures. The shape and function of this Arena created an unprecedented experience for Venice. The entrance was through a soft curtained threshold that allowed regular movement, rather than an open or closed door that would confine access to a strictly punctuated schedule. With a wide passageway running between the stage and the three-sided seated area it was in part an agora and also a mini amphitheater. The public could pass through or pause and settle. Hence the modes of attention to the events in the Arena ranged from the ambient assemblage of fragments to focused spectatorship. The identity of the Arena was dominated by the bright communist red carpet and the daily readings from Karl Marx's Das Kapital (directed by the artist Isaac Julien and curator Mark Nash). The emphasis given to Marx's analysis of surplus production, class relations and 
the universalization of money as a unit of value, the inclusion of seminars organized by e-flux journal, a symposium organized by Creative Time, performances coordinated by socially engaged artist Jeremy Deller and the surrounding work by artists such Isaac Julien, Rirkrit Tiravanija, Teresa Burga and Adrian Piper made pointed connections to the complicities between contemporary art and global capitalism. These discursive projects carried an urgency and affective appeal that cannot be reduced to an academic lecture.

The insertion of the Arena as the "Biennale's central nervous system" 39 conveys two bold art historical propositions: first, it declares that the discursive turn is not confined to ephemeral events that are either appended to the body of an exhibition, or physically located in the margins of the building - it is now a central feature in the institution of contemporary art. Through this elevation of the function of the arena we can finally admit the significance of Arthur C. Danto's definition of the term "artworld.” In 1964 Danto defined artworld as the emergence of both the social rules and classificatory activities observed by a community of interpreters, and "something that the eye cannot descry, an atmosphere of art theory." 40 Thus the relationship between art and world was framed by the premise: an object on its own does not commune with the world. For an object to enter the world as an aesthetic object it had to be filtered through an atmosphere of theory. Secondly, the post-colonial subjectivities and post-industrial landscapes that were juxtaposed in documenta XI are now interwoven into a knotted form of global precarity. The South and the North have inter-penetrated each other to such an extent that it may no longer be possible to discretely celebrate creativity in the former and critique the latter as the source of oppression.

These propositions on the entanglement of North and South, art and politics, ethics and aesthetics also framed Enwezor's installation of artworks in the other major venue of the Venice Biennale. The Corderie - the former rope factory of the Arsenale - has often been used as if it were a long passage with discrete booths running off the spine. Such uses tended to encourage a blaze attitude among spectators as they paraded between the dazzling array of artworks form around the world. Enwezor's installation of art in the Corderie made it physically impossible to stroll along in a straight line. One was compelled to choose between divergent paths, enter into cul de sacs and in many cases double back to "retrieve" the work of art you aimed for. The "passagiata" through the field of contemporary art was disrupted by a sequence of looping, disjunctive and uncanny encounters. The sharing of the opening space between 
Bruce Nauman's classic neon work Eat Death, 1972, and Adel Abdessemed's Nympheas, 2015, in which long knives were inserted as bouquets of lilies in the dark ground both initiated the zig-zag route between object and symbols and embodied the exhibition's disjunctive aesthetic. At the midway point of the Corderie was the work of the Italo-Australian artist Marco Fusinato From the Horde to the Bee, 2015. It was a wide table loaded with books that occupied the center of the corridor. The stack of identical books resembled a fortress. Inside the table was an open space. The artist had produced a publication from the Moroni archive. The book documented a history of public notifications and militant writings generated by a Milan based activist community. Fusinato invited the viewers to make a donation and take one of the books. As the wall of books diminished the money from the previous donations became tantalizingly accessible. In this work there was no legal barrier between gift and theft.

The orchestration of space in this biennale played with the senses in peculiar ways. It gave stress to the role of orality and half-light, and through the ambient dispersal of textured sounds and in dim pre-apprehension of things, it summoned the process of sensing that precedes thought. The Arena and the Corderie served as a chora - receptacle, interval and clearing - for the pre-signifying state and non-expressive totality of drives from which the choreography of diasporic displacement and precarious living are constituted. By zooming into the specific worlds of each artwork in the exhibition there was the challenge to focus on the actually existing interplay between a moral imperative for conviviality and an aesthetic interest in difference. Zooming out allows us to reflect on the discursive structure of the exhibition as a whole. From this altitude another cosmological quest appears: one that starts from the zones of pre-signification and opens up the spacing of presence. However, it also brings into light the complex entanglements of the South and the North. As the ideological and regional distinctions collapse and blur, the relational value of this imbrication has become more layered, and the heading of each of these oppositional categories has also come to an end. The South is in the North and vice-versa.

\section{NOTES}

1. Gerardo Mosquera, "Alien-own/own Alien," in Complex Entanglements: Art, Globalization and Cultural Difference, ed. Nikos Papastergiadis (London: Rivers Oram Press, 2003), 19-29.
2. Antonio Gramsci, Pre-Prison Writings, ed. Richard Bellamy, translation by Virginia Cox (Cambridge: Cambridge University Press, 1994). 
3. See for instance the think-make-do tank Movement Net Lab and the activist network Global Movement for the Global South.

4. Jan Nederveen Pieterse, "What is Globalization," in Globalizations: What is Global Studies?, Globalizations, DOI: 10.1080/14747731.2013.806746 (accessed 2 March 2016).

5. Pedro Figari, "Regional Autonomy," reprinted in Readings in Latin American Modern Art, ed. Patrick Frank (New Haven: Yale University Press, 2004).

6. Sur survived until 1991 , and over its time it recognized numerous authors such as Borges and Camus long before they achieved international acclaim. For instance, in 1939 Victoria Ocampo invited Roger Caillois from Paris to give a six week lecture in Buenos Aires, he stayed for the duration of the Second World War, edited a literary review in exile, and on his return published a collection of translations of South American authors: "La Croix du Sud." See Doris Meyer, Victoria Ocampo, Against the Wind and the Tide (Austin: University of Texas Press, 1990).

7. Carmelo Strano (ed.), II Sud del Mondo: L'Altra Arte Contemporanea (Milan: Mazzota, 1991), 155.

8. Ibid., 170.

9. Bernard Smith, Place, Taste and Tradition: a study of Australian art since 1788 (Sydney: Ure Smith, 1945) and Bernard Smith, European Vision and the South Pacific, 1788-1850: a study in the history of art and ideas (Oxford: Clarendon Press, 1960).

10. Peter Beilharz, Thinking the Antipodes (Melbourne: Monash University Press, 2015).

11. Nikos Papastergiadis, "Can there be a history of contemporary art?," Discipline, no. 2, 2012: 152-6.

12. Ian Wedde, How to Be Nowhere: Essays and Texts, 19711994 (Wellington: Victoria University Press, 1995).

13. Ian Wedde, "The Embarkation from Cythera," in Carmelo Strano (ed.), op.cit., 212.

14. Nikos Papastergiadis and Meredith Martin, "Art biennales and cities as platforms for global dialogue," in Festivals and the Cultural Public Sphere, ed. L. Giorgi, M. Sassatelli and G. Delanty (London: Routledge, 2011), 45-62.

15. Nikos Papastergiadis (ed.), Complex Entanglements: Art, Globalisation and Cultural Difference (London: Rivers Oram Press, 2003); Scott McQuire and Nikos Papastergiadis (eds.), Empires, Ruins + Networks: The Transcultural Agenda in Art (Melbourne: Melbourne University Press, 2005).

16. Kevin Murray, "Keys to the South," Australian Humanities Review, 44., 2008: http://www. australianhumanitiesreview.org/archive/IssueMarch-2008/murray.html (accessed 2 March 2016); Anthony Gardner (ed.), Mapping South: Journeys in South-South Cultural Relations (Melbourne: South Project, 2013).

17. Medina Cuauhtemoc (ed.), South, South, South, South (Mexico City: SITAC, 2010), 12.

18. Okwui Enwezor, "The Black Box", in Documenta 11 Platform 5: Exhibition Catalogue (Osterfilden: Hatje Cantz, 2002), 42.

19. Okwui Enwezor, "The Artist as producer in Times of Crisis," in Empires, Ruins + Networks, ed. S. McQuire and N. Papastergiadis (Melbourne: Melbourne University Press, 2005), 11-51.

20. Charles Esche, Modest Proposals (Istanbul: Baglam, 2005), 12.
21. Cuauhtemoc Medina, "Seeing Red," in Art in the Global Present, ed. N. Papastergiadis \& V. Lynn (Sydney: UTS Press, 2014), 140.

22. Ranjit Hoskote, "Global Art and Lost Regional Histories," in N. Papastergiadis \& V. Lynn (eds.), op.cit., 192.

23. Okwui Enwezor, "Mega-Exhibitions and the Antinomies of a Transnational Global Form," Manifesta Journal, no. 2, 2004, pp. 9-22.

24. Raewyn Connell, Southern Theory (Sydney: Allen \& Unwin, 2007).

25. Lee Weng Choy, "A Country of Last Whales - Contemplating the Horizon of Global Art History; Or, Can we Ever Really Understand How Big the World Is?," Third Text, vol. 25, no. 4, 2011: 457.

26. Beilharz, op.cit., 38.

27. Raul Moarquech Ferrera-Balanquet and Miguel RojasSotelo, "Decolonial AestheSis at the $11^{\text {th }}$ Havana Biennial," in Social Text, 2013: socialtextjournal.org/periscope_ article/decolonial-aesthesis-at-the- $11^{\text {th }}$-havana-biennial/, pp, 133-156. (accessed 2 March 2016).

28. Walter Mignolo, "The Argument (as manifesto for decolonial aesthetics)," The Center for Global Studies and the Humanities website, 2013: https://globalstudies.trinity. duke.edu/the-argument-as-manifesto-for-decolonialaesthetics. (accessed 2 March 2016).

29. Walter Mignolo, "The North of the South and the West of the East," 2015: http://www.ibraaz.org/essays/108 (accessed 12 July 2015).

30. Anne Ring Petersen, "Global art history: a view form the North," Journal of Aesthetics \& Culture, vol. 7, 2015: http//dx.doi.org/10.3402/jac.v7.28154 (accessed 2 March 2016).

31. Isabell Stengers, Cosmopolitics II, translated by R. Bononno (Minneapolis: Minnesota University Press, 2011).

32. Christian De Beukelaer, M. Pyykkonen \& J.P. Singh (eds.), Globalization, Culture and Development (London: Palgrave, 2016).

33. David Tey: https://www.youtube.com/ watch?v=SINiOFdEFjU, 2015 (accessed 2 March 2016).

34. Hans Belting and Anna Buddensieg (eds.), The Global Art World: Audiences, Markets and Museums (Ostfildern: Hatje Cantz, 2009).

35. Natasha Ginwala, “Maps that don't Belong," http://www. ibraaz.org/essays/120, 2015 (accessed 10 July 2015).

36. Jean-Luc Nancy, Multiple Arts: The Muses II, ed. Simon Sparks (Stanford: Stanford University Press, 2006), 195.

37. Emily Kame Kngwarreye's painting of a creation story is similar to the ones that inspired Western artists like Anselm Kiefer. See his keynote lecture at the 1992 Adelaide festival, "Boundaries, Tracks, Traces, Songs," Art and Australia, vol. 30, no. 2, 1992, 3-11.

38. As an index of increased levels of visibility and competitiveness of non-Western artists Anne Ring Petersen cites a survey that reveals a leap from $5 \%$ representation in the first documenta (1955) to $50 \%$ in the $\mathbf{2 0 0 2}$ documenta. Anne Ring Petersen, "Identity politics, Institutional Multiculturalism, and the Global Artworld," Third Text, vol. 26, iss. 2, pp. 195-204.

39. Okwui Enwezor and Michelle Kuo, "Global Entry," Artforum, vol. 53, no. 9, May, 2015: 86.

40. Arthur C. Danto, "The Artworld," The Journal of Philosophy, vol. LXI, 1964, pp. 571<-584. 